EUROPA REGIONUM TOM XXIII ROK 2015

DOI: $10.18276 /$ er.2015.23-21

\author{
ANNA BIAŁK-WolF \\ Wyższa Szkoła Turystyki i Hotelarstwa w Gdańsku
}

\title{
Kulturowy aspekt ekoturystyki w rozwoju regionalnym
}

\section{Wprowadzenie}

$\mathrm{K}$ ultura może być traktowana jako zasób regionu. Najczęściej jest określana jako zestaw norm, zwyczajów i zachowann ${ }^{1}$. Inne ważne jej przejawy dotyczą zaufania, respektowania innych i pewności w zakresie uzyskiwania pozytywnych efektów włożonej pracy ${ }^{2}$. Kultura należy do tzw. miękkich czynników lokacyjnych, które jest trudno uchwycić i zmierzyć ${ }^{3}$. Pojęcie kultury obejmuje też kulturę życia codziennego. Jest ona trudna do naśladowania i imitacji, co może z kolei pozytywnie przyczynić się do osiagnięcia przewagi konkurencyjnej danego regionu. ,

Z kolei najczęściej przytaczaną definicją ekoturystyki jest ta autorstwa Międzynarodowego Towarzystwa Ekoturystycznego, mówiąca o tym, iż ekoturystyka to „świadoma podróż do naturalnych miejsc przyrodniczych, która z jednej strony pomaga chronić środowisko naturalne, a z drugiej podtrzymuje dobrobyt lokalnych mieszkańców"4. Mimo częstego cytowania powyższej definicji panuje jednakże przekonanie, iż nie istnieje jedna uniwersalna definicja tego pojęcia. Na potwierdzenie tej tezy warto przytoczyć fakt, iż D. Fennell ${ }^{5}$ zidentyfikował aż 85 definicji ekoturystyki.

${ }^{1}$ H. Briassoulis, Sustainable Tourism and the question of the commons, ,Annals of Tourism Research" 2002, vol. 29, no. 4, s. 1067.

${ }^{2}$ G. Tabellini, Culture and Institutions: Economic Development in the Regions of Europe, „Journal of the European Economic Association" 2010, vol. 8, no. 4, s. 679.

${ }^{3}$ H. Pechlaner, E. Innerhofer, M. Bachinger, Standortmanagement und Lebensqualität, w: H. Pechlaner, M. Bachinger, (red.), Lebensqualität und Standortattraktivität: Kultur, Mobilität und regionale Marken als Erfolgsfaktoren, Berlin 2010, ESV-Verlag, s. 13-34.

${ }^{4}$ R. N. Okech, Developing urban ecotourism in Kenyan cities: A sustainable approach, ,Journal of Ecology and Natural Environment" 2009, vol. 1, no. 1, s. 1.

5 D. Fennell, A content analysis of ecotourism definitions, „Current Issues in Tourism” 2001, vol. 4, s. 403-421. 
Generalnie można wskazać na dwie grupy definicji. Po pierwsze są to definicje normatywne, które zakładają, iż pojęcie to powinno być stosowane zgodnie z wcześniej przyjętymi zasadami. Drugą grupę tworzą definicje deskrypcyjne, w których analizuje się użycie tego pojęcia w praktyce. Brak zgodności w zakresie definiowania tego terminu wynika również z faktu, iż ekoturystyka stała się nie tylko pojęciem naukowym, ale także politycznym. Co więcej, zarówno zachowanie pojedynczego turysty, jak również struktura pakietu turystycznego może zawierać elementy kwalifikujące daną podróż jako ekoturystykę, oraz inne elementy, które jednocześnie to wykluczają. Ponadto, nastawienie do różnych aspektów ekoturystyki różni się nie tylko wśród poszczególnych interesariuszy, ale także między państwami i tradycjami kulturowymi. Te czynniki wpływają na trudności w stworzeniu uniwersalnej definicji tego pojęcia ${ }^{6}$.

Występują dwa skrajne podejścia do zagadnienia ekoturystyki. Z jednej strony wyróżnia się holistyczny model ekoturystyki, w którym podkreśla się systemowy charakter ekoturystyki, składającej się z połączonych i zintegrowanych jednostek. $\mathrm{Z}$ drugiej strony identyfikuje się cząstkowe podejście, gdy następuje koncentracja zainteresowania wyłącznie na wybranych aspektach środowiska, które wydają się szczególnie atrakcyjne. Należy podkreślić, iż aspekty kulturowe zdecydowanie częściej pojawiają się w podejściu holistycznym, które integruje działalność człowieka w ekosystem? ${ }^{7}$.

Analiza różnych definicji ekoturystyki wskazuje, iż oprócz aspektów dotyczących środowiska naturalnego pojawiają się także takie elementy, jak: edukacja ekologiczna, zaangażowanie lokalnych społeczności, podróżowanie w małych grupach, znaczenie lokalnej kultury, mała skalę występowania, zyski finansowe dla lokalnej społeczności, możliwość spędzenia czasu z rodziną ${ }^{8}$. R.E. Krider i in. ${ }^{9}$ twierdzą, iż generalnie w definicjach ekoturystyki dominuje pięć obszarów: środowisko naturalne, ochrona, kultura, korzyści dla lokalnej ludności i edukacja. Również w polskim obszarze językowym podkreśla się, iż ekoturystyka jest ,ściśle związana z przyrodą i rdzenną kulturą obszarów o wysokich walorach naturalnych"10.

\footnotetext{
${ }^{6}$ R. Buckley, Defining ecotourism: consensus on core, disagreement on detail, w: International Handbook on Ecotourism, R. Ballantyne, J. Packer, (red.) Edward Ekgar Publishing Limited, UK, 2013, s. 9.

${ }^{7}$ D. Weaver, Comprehensive and minimalist dimension of ecotourism, „Annals of Tourism Research" 2005, vol. 32, no 2, s. 440-441, 444.

8 J. Higham, M. Lück, Urban Ecotourism: A Contradiction inTerms?, „Journal of Ecotourism” 2002, vol. 1, no 1, s. 37-38; W. Lu, S. Stepchenkova, Ecotourism experiences reported online: Classification of satisfaction attributes, „Tourism Management” 2012, vol. 33, s. 703.

${ }^{9}$ R.E. Krider, A. Arguello, C. Campbell, S. Fraser, J.D. Mora, Trait and Image Interaction in Ecotourism Preference, ,Annals of Tourism Research” 2010, vol. 37, no 3, s. 780.

${ }^{10}$ D. Zaręba, Ekoturystyka, Wydawnictwo Naukowe PWN, Warszawa 2006, s. 36.
} 
Należy zauważyć, iż szczególne miejsce wśród definicji ekoturystyki zajmuje edukacja oraz kultura, przy czym motyw edukacyjny ekoturystyki można potraktować jako przejaw motywacji kulturowych ${ }^{11}$. Tak więc definicje ekoturystyki oferują najczęściej kombinację ochrony ekologicznej i kulturowej oraz podniesienie lokalnej świadomości w zakresie ochrony tychże walorów.

Kolejnego argumentu na rzecz istotnej roli kultury w rozwoju ekoturystyki dostarcza analiza charakterystyki samych ekoturystów. Studia przypadków pokazują iż są dla nich istotne nie tylko elementy związane bezpośrednio ze środowiskiem naturalnym, ale również zasoby kulturowe ${ }^{12}$. Badanie przeprowadzone przez S. Dolnicar i in. ${ }^{13}$ wskazują, iż w $20 \%$ zidentyfikowanych definicjach ekoturystów pojawiają się elementy kultury (zainteresowanie, poszanowanie, zaangażowanie) jako ważne części składowe podróży.

Podsumowując można więc wykazać, iż związki między ekoturystyką a kulturą są wielopłaszczyznowe i dotyczą następujących elementów:

- zachowanie dziedzictwa kulturowego stanowi element wielu definicji ekoturystyki,

- budowanie kulturowej świadomość uczestników ruchu turystycznego stanowi jedno z głównych zadań ekoturystyki ${ }^{14}$,

- wspieranie dobrobytu lokalnych mieszkańców stanowi również cel ekoturystyki, a główną cechą tychże mieszkańców jest ich kultura,

- kultura stanowi obok środowiska naturalnego główny zasób regionów, którego ochrona powinna być celem zarządzania zrównoważonego,

- przyjmuje się, iż ekoturystyka stanowi trzon turystyki zrównoważonej, w której element kultury jest mocno akcentowany,

- pojawiają się koncepcje filozoficzne (taoizm, konfucjanizm), w myśl których podkreśla się, iż kultura nie jest przeciwstawieństwem natury, a „człowiek wraz ze swoją działalnością jest częścią" "15,

- badanie wskazują iż kultura stanowi ważny motyw podróży ekoturystów.

\footnotetext{
${ }^{11}$ A.M. v. Rohrscheidt, Turystyka kulturowa - wokót definicji, „Turystyka Kulturowa” 2008, nr 1, www.turystykakulturowa.org, s. 18.

${ }^{12}$ W. Lu, S. Stepchenkova, Ecotourism..., s. 703.

${ }^{13}$ S. Dolnicar, V. Yanamandram, E. Juvan, Ecotourists: who are they and what should we really call them?, w: Handbook..., s. 98.

${ }^{14}$ A. Kaczmarska Możliwości rozwoju agro- $i$ ekoturystyki w Polsce na przykladzie województwa ślaskiego, „Oeconomia” 2010, nr 9 (4), s. 214-215.

${ }^{15}$ J. Higham, M. Lück, Urban Ecotourism...,., s. 38, R. Buckley, C. Catar, Z. Linsheng, T. Chen, SHENGTAI LUYOU: Cross-Cultural Comparison in Ecotourism, „Annals of Tourism Research” 2008, vol. 35 , no. 4, s. 960 .
} 


\section{Wpływ kultury na rozwój regionalny}

Istniej wiele badań dotyczących wpływu kultury na rozwój regionalny ${ }^{16}$. Wykazano też związki między kulturą a rozwojem turystyki na danym terenie ${ }^{17}$. Szczególną rolę w przypadku wpływu ekoturystyki na rozwój regionu ma kultura regionu, którą można opisać jako „system wspólnych wierzeń, ideologii, zrozumienia i konwencji”"18. Do wyjaśnienia związków między ekoturystyką a rozwojem regionalnym może okazać się pomocny jeden z paradygmatów nowej ekonomii instytucjonalnej, w myśl którego w kulturze upatruje się możliwości wyjaśnienia różnic $\mathrm{w}$ rozwoju poszczególnych regionów ${ }^{19}$. Czynniki zaliczane do sfery kultury mogą być więc uznane za elementy przesądzające o powodzeniu danego regionu. Wynika to $\mathrm{z}$ faktu, iż to kultura danego regionu wpływa na to, czy jesteśmy w stanie sobie zaufać, czy jesteśmy skłonni do ryzyka i na ile jesteśmy otwarci na nowości ${ }^{20}$. Te czynniki z kolei mają bezpośredni wpływ na innowacyjność i przedsiębiorczość $\mathrm{w}$ regionie, będące niekwestionowaną podstawą rozwoju. To właśnie niematerialne i trudno uchwytne elementy, takie jak np. zaufanie mogą się stać bazą tworzenia efektywnych więzi gospodarczych ${ }^{21}$.

\section{Rola kultury w rozwoju ekoturystyki i fundamentalne znaczenie lokalnych społeczności}

Kultury danego regionu nie można analizować w oderwaniu od jego mieszkańców, gdyż to oni są jej głównym nośnikiem. Duże znaczenie w konsumpcji turystycznej mają dobra niematerialne, obejmujące głównie kulturę,

\footnotetext{
${ }^{16}$ Przykładowo: Y. Aoyama, Entrepreneurship and Regional Culture: The Case of Hamamatsu and Kyoto, ,„Japan Regional Studies” 2009, vol. 43, no. 3, s. 495-512; G. Tabellini, Culture and Institution...; J. Heley, G. Gardner, S. Watkin, Cultures of local economy in a Celtic fringe region, „European Urban and Regional Studies" 2011, vol. 19, no. 4, s. 366-382.

${ }^{17}$ A. Białk-Wolf., H. Pechlaner, C. Nordhorn, The role of culture in building regional innovation systems and its impact on business tourism - The case of the Nuremberg Metropolitan Region, Poznan „University of Economics Review", 2013, vol. 13, no. 4, 2013 s. 111-128.

${ }^{18}$ James, A., Demystifying the Role of Culture in Innovative Regional Economies, „Regional Studies" 2005, vol. 39, no. 9, s. 1199.

${ }^{19}$ K. Kostro, Zagadnienia kulturowe w ekonomii, Gospodarka Narodowa, 2009, nr 3, s. 51-52.

${ }^{20}$ F. Tödling, P. Van Reine, S. Dörhöfer, Open Innovation and Regional Culture - Findings from Different Industrial and Regional Settings, „European Planning Studies” 2011, vol. 19, no. 11, s. 1887.

${ }^{21}$ Potwierdzenie tej tezy znajdziemy w badaniach K. Czernek, Instytucje jako uwarunkowania wspótpracy $w$ regionie turystycznym - ujęcie z perspektywy nowej ekonomii instytucjonalnej, w: Prace Naukowe Uniwersytetu Ekonomicznego we Wrocławiu, „Gospodarka turystyczna w regionie. Przedsiębiorstwo. Samorząd. Współpraca” 2011, nr 157, s. 401-4011.
} 
a także szersze pojęcie, które można określić jako „,charakter miejsca”,22, w dużej mierze również determinowany przez mieszkańców. Wśród naukowców panuje zgoda odnośnie do istotnej roli rdzennych mieszkańców w rozwoju ekoturystyki. Są oni traktowani jako jej beneficjenci i szerzej - jako główni jej interesariusze ${ }^{23}$.

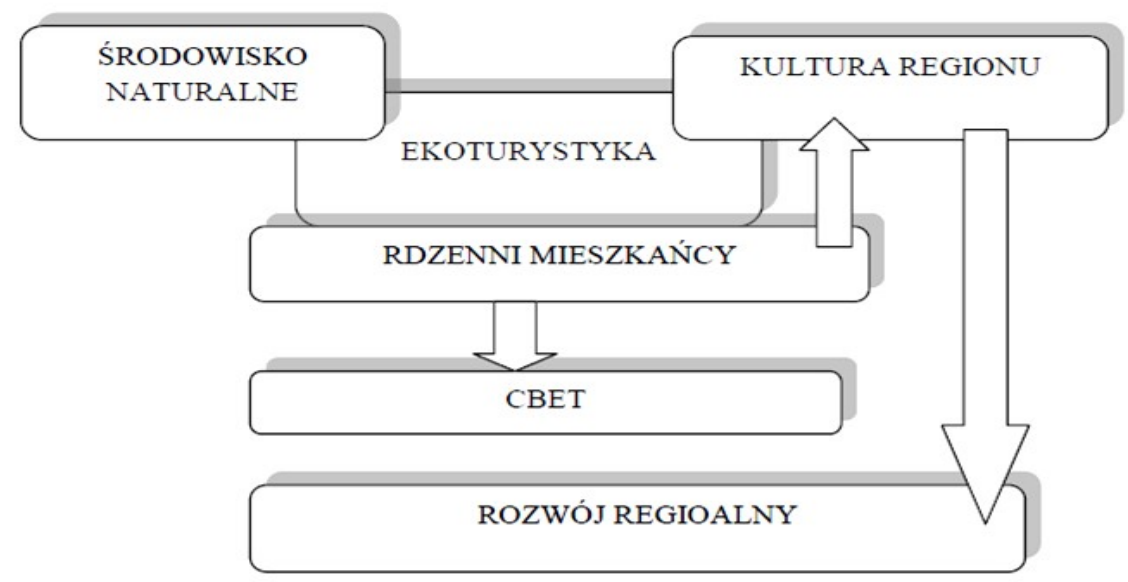

Rysunek1. Wpływ kultury jako elementu ekoturystyki na rozwój regionalny Źródło: opracowanie własne.

W literaturze ekoturystyka jest często analizowana w kontekście koncepcji community-based tourism, gdzie podkreśla się, że celem rozwoju turystyki na danym terenie jest odrodzenie i zachowanie tradycyjnej kultury miejscowej ludności i sposobu ich życia. Myśl ta została rozwinięta jako community-based ecotourism i uznana za formę zrównoważonego rozwoju społeczności ${ }^{24}$, która ma za zadanie wspierać ochronę środowiska, kulturę a także umożliwić lokalnej społeczności generowanie nowych źródeł pozyskiwania środków do życia ${ }^{25}$. Kluczowym jej elementem jest własność prywatna danej społeczności i podejmowanie decyzji dotyczących rozwoju turystyki właśnie przez społeczności lokalne ${ }^{26}$, stanowiące kom-

${ }^{22}$ H. Briassoulis, Sustainable...., s. 1067.

${ }^{23} \mathrm{H}$. Zhang, S. L. Lei, A structural model of residents' intention to participate in ecotourism: The case of a wetland community, „Tourism Management” 2012, vol. 33, s. 916.

${ }^{24}$ A. Stronza, J. Gordillo, Community Views of Ecotourism, „Annals of Tourism Research” 2008, vol. 35, no. 2, s. 448-468.

${ }^{25}$ L. Tran, P., Walter Ecotourism, gender and development in northern Vietnam, „Annals of Tourism Research" 2014, vol. 44, s. 116.

${ }^{26}$ C. Byczek, Blessings for All? Community-Based Ecotourism in Bali Between Global, National, and Local Interests - A Case Study, ASEAS - „Austrian Journal of South-East Asian Studies" 2011, 4, s. 81-106. 
binację przestrzeni, ludzi i społecznych interakcji między nimi. W analizie tej koncepcji zwraca się jednakże uwagę na problemy dotyczące samego pojęcia społeczności (community), gdyż są one są bardzo zróżnicowane wewnętrznie ${ }^{27}$.

Synteza wiedzy z zakresu ekoturystyki, koncepcji community-based ecotourism oraz wpływu kultury na rozwój regionalny ukazuje, iż to mieszkańcy danego regionu mogą stanowić kluczowy czynnik umożliwiający rozwój regionu. Pozwala ona także na stworzenie teoretycznego modelu ukazującego wzajemne powiązania i między analizowanymi elementami. Zostało to przedstawione na rysunku 1.

\section{Podsumowanie}

Jak wykazano w części pierwszej niniejszego referatu, kultura wykazuje szczególne znaczenie w ekoturystyce, która bazuje głównie na roli społeczności lokalnej. Również zagadnienie zasobów kulturowych wiąże się nierozerwalnie z problematyką lokalnych mieszkańców. Analiza ekoturystyki poprzez jej kulturowe aspekty pokazuje, iż kluczowym czynnikiem umożliwiającym jej rozwój jest kapitał społeczny na danym terenie. Związki te są wielorakie. Po pierwsze, rdzenni mieszkańcy są nośnikiem kultury, a więc inwestycje w kapitał społeczny przyczyniają się do rozwoju kultury na danym terenie. Ta z kolei ma bezsprzecznie pozytywny oddźwięk nie tylko w zakresie wzrostu zainteresowania danym terenem przez turystów (kultura to ważny czynnik motywujący ekoturystów), ale również staje się ciekawym miejscem dla potencjalnych nowych mieszkańców, przyciaga inwestycje, a w konsekwencji przyczynia się do szeroko pojmowanego rozwoju gospodarczego regionu ${ }^{28}$. Co więcej rozwój kapitału społecznego zwiększa świadomość na temat roli kultury, ekologii, a także poczucia wpływu na własne życie i umiejętności podejmowania decyzji, co z kolei stanowi bazę community-based ecotourism. Pewnego wsparcia tej tezy dostarczają badania H. Zhang i S. Lei ${ }^{29}$, zgodnie z którymi wiedza miejscowej ludności na temat środowiska naturalnego pozytywnie wpływa na stosunek do rozwoju ekoturystyki na tym obszarze. Z kolei badania M. Iorio i G. Wall ${ }^{30}$ wskazują, iż decydujący wpływ na rozwój turystyki w regionie ma charakterystyka lokalnych mieszkańców. Nawet jeśli

\footnotetext{
${ }^{27}$ M. Iorio, G. Wall, Behind the masks: Tourism and community in Sardinia, „Tourism Management" 2012, no. 33, s. 1441.

${ }^{28}$ R. Scherer, Synergien zwischen Standortmarketing, Wirtschaftsförderung und Tourismusmarketing, w: Pechlaner, H., Bachinger, M. (red.), Lebensqualität und Standortattraktivität. Kultur, Mobilität und regionale Marken als Erfolgsfaktoren, Erich Schmidt Verlag, Berlin 2010, s. 286.

${ }^{29} \mathrm{H}$. Zhang, S. Lei, A structural model of residents' intention to participate in ecotourism: The case of a wetland community, „Tourism Management” 2012, vol. 33, s. 916-925.

${ }^{30}$ M. Iorio, G. Wall, Behind the masks ..., s. 1440-1449.
} 
autorzy ci nie posługują się w omawianym artykule pojęciem kultury, to zgodnie z przyjętą na wstępie definicją, analizowane przez nich cechy lokalnych mieszkańców można zaliczyć do aspektów kultury regionu.

Podsumowując można przyjąć, iż rozwój kultury wpływa zarówno na stronę popytową, jak i podażową ekoturystyki, a w dalszej perspektywie przyczynia się do rozwoju regionu. Połączenie dwóch zagadnień (rozwoju regionalnego i ekoturystyki) ukazało możliwości rozwoju ekoturystyki poprzez aspekt kulturowy, który to może przyczynić się do rozkwitu regionu zgodnie z zasadami zrównoważonego rozwoju, przy czym podstawę tego rozwoju stanowią rdzenni mieszkańcy. Można stwierdzić, iż występują silne związki synergiczne między rozwojem kultury w regionie i ekoturystyką w oparciu o miejscową ludność. Zagadnienie to wymaga jednakże dalszych badań empirycznych.

\section{Bibliografia}

Aoyama, Y., Entrepreneurship and Regional Culture: The Case of Hamamatsu and Kyoto, „Japan Regional Studies”, vol. 43, no. 3, 2009, s. 495-512.

Białk-Wolf, A., Pechlaner, H., Nordhorn C., The role of culture in building regional innovation systems and its impact on business tourism - The case of the Nuremberg Metropolitan Region, „Poznań University of Economics Review” 2013, vol. 13, no. 4, s. $111-128$.

Briassoulis, H., Sustainable Tourism and the question of the commons, „Annals of Tourism Research" 2002, vol. 29, no. 4, s. 1065-1085.

Buckley, R., Defining ecotourism: consensus on core, disagreement on detail, w: International Handbook on Ecotourism, R. Ballantyne, J. Packer (red.), Edward Ekgar Publishing Limited, UK, 2013, s. 9-14.

Buckley, R., Catar, C., Linsheng, Z., Chen, T., SHENGTAI LUYOU: Cross-Cultural Comparison in Ecotourism, „, Annals of Tourism Research”2008, vol. 35, no. 4, s. 945-968.

Czernek, K., Instytucje jako uwarunkowania wspótpracy w regionie turystycznym - ujęcie z perspektywy nowej ekonomii instytucjonalnej, w: Prace Naukowe Uniwersytetu Ekonomicznego we Wrocławiu, „Gospodarka turystyczna w regionie. Przedsiębiorstwo. Samorząd. Współpraca” 2011, nr 157, s. 401-411.

Dolnicar, S., Yanamandram, V., Juvan, E., Ecotourists: who are they and what should we really call them?, w: International Handbook on Ecotourism, R. Ballantyne, J. Packer (red.), Edward Ekgar Publishing Limited, UK, 2013, s. 95-107.

Fennell D., A content analysis of ecotourism definitions, „Current Issues in Tourism” 2001, vol. 4, s. 403-421.

Heley, J., Gardner, G., Watkin, S., Cultures of local economy in a Celtic fringe region, „European Urban and Regional Studies" 2011, vol. 19, no. 4, s. 366-382.

Higham J., Lück M., Urban Ecotourism: A Contradiction in Terms? „Journal of Ecotourism” 2002, vol. 1, no. 1, s. 36-51.

Iorio M., Wall G., Behind the masks: Tourism and community in Sardinia, „Tourism Management" 2012, no. 33, s. 1440-1449. 
James, A., Demystifying the Role of Culture in Innovative Regional Economies, „Regional Studies" 2015, vol. 39, no. 9, s. 1197-1216.

Kaczmarska A., Możliwości rozwoju agro- i ekoturystyki w Polsce na przykładzie województwa ślaskiego, „Oeconomia” 2010, nr 9 (4), s. 211-223.

Kostro, K., Zagadnienia kulturowe w ekonomii, „Gospodarka Narodowa” 2009, nr 3, s. 27-59.

Krider R.E., Arguello A., Campbell C., Fraser S., Mora J.-D., Trait and Image Interaction in Ecotourism Preference, „Annals of Tourism Research” 2010, vol. 37, no. 3, s. 779-801.

Lu W., Stepchenkova, S., Ecotourism experiences reported online: Classification of satisfaction attributes, „Tourism Management”2012, vol. 33, s. 702-712.

Okech R. N., Developing urban ecotourism in Kenyan cities: A sustainable approach, „Journal of Ecology and Natural Environment" 2009, vol. 1, no. 1, s. 1-6.

Pechlaner, H., Innerhofer, E., Bachinger, M., Standortmanagement und Lebensqualität, w: Pechlaner, H., Bachinger, M. (red.), Lebensqualität und Standortattraktivität: Kultur, Mobilität und regionale Marken als Erfolgsfaktoren, ESV-Verlag, Berlin, 2010, s. 13-34.

Rohrscheidt A.M., Turystyka Kulturowa - wokót definicji, „Turystyka Kulturowa” 2008, nr 1, www.turystykakulturowa.org, s. 4-21.

Scherer, R., Synergien zwischen Standortmarketing, Wirtschaftsförderung und Tourismusmarketing, in: Pechlaner, H., Bachinger, M. (red.), Lebensqualität und Standortattraktivität. Kultur, Mobilität und regionale Marken als Erfolgsfaktoren, ESV-Verlag, Berlin 2010, s. 275-290.

Stronza, A., Gordillo, J., Community Views of Ecotourism, „Annals of Tourism Research” 2008, vol. 35 , no. 2 , s. $448-468$.

Tabellini, G., Culture and Institutions: Economic Development in the Regions of Europe, ,Journal of the European Economic Association" 2010, vol. 8, no. 4, s. 677-716.

Tran, L., Walter, P., Ecotourism, gender and development in northern Vietnam, „Annals of Tourism Research" 2014, vol. 44, s. 116-130.

Tödling, F., Van Reine, P., Dörhöfer, S. Open Innovation and Regional Culture - Findings from Different Industrial and Regional Settings, ,European Planning Studies” 2011, vol. 19, no. 11, s. 1885-1907.

D. Weaver, Comprehensive and minimalist dimension of ecotourism, ,Annals of Tourism Research" 2005, vol. 32, no. 2, s. 439-455

Zaręba D., Ekoturystyka, Wydawnictwo Naukowe PWN, Warszawa 2006.

Zhang H., Lei S. L., A structural model of residents' intention to participate in ecotourism: The case of a wetland community, „Tourism Management” 2012, vol. 33, s. 916-925.

\section{Culture as an element of ecotourism in regional development}

\section{Summary}

This paper addresses questions regarding the culture as an element of ecotourism. Having demonstrated that the term "ecotourism" is only vaguely defined, reasons for this shortfall are presented, whereupon the paper continues with examining the interplay between ecotourism and culture. Culture is shown to be a phenomenon shaping the regional development. An interesting theoretical basis for further considerations is provided by the concept of "community-based ecotourism". The paper ends with the proposal of a theoretical framework highlighting the role of culture as an element of ecotourism and its impact on regional development.

Translated by: Anna Biatk-Wolf 